\title{
THE EFFECTS OF VITAMIN A ON TEAR BREAK-UP TIME OF YOUNG ADULTS
}

\author{
BY \\ IWUAGWU, F. O., AGU, G. C., AZUAMAH, Y. C. AND OKOLIE, V.U. \\ *DEPARTMENT OF OPTOMETRY, IMO STATE UNIVERSITY \\ OWERRI, IMO STATE, NIGERIA \\ Email:frankiwuagwu@yahoo.com \\ *Corresponding author
}

\begin{abstract}
This study was carried out to determine the effect of increased intake of vitamin A on Tear break-up time (TBUT). One hundred asymptomatic healthy young adults; 50 males and 50 females all within the ages of 18 and 30 years were used for this study. Results showed a range of 13-28 seconds and a mean TBUT of 19.12 seconds before the administration of vitamin A. After 20 days of a seven-day administration of vitamin A, the range becomes 16-31 seconds and a mean TBUT of 21.79 seconds. This showed an increase of 2.67 seconds in the mean TBUT. Measuring the correlation between the observations using the Spearman rank- order correlation coefficient at 0.05 level of significance, there was a significant improvement in TBUT after the administration of vitamin A.
\end{abstract}

\section{INTRODUCTION}

Vitamin A (retinol) is a long-chained alcohol found in the fat of milk, and therefore in butter and cream. It is also found in eggs and liver fat, but mainly in fish. Liver oil such as cod-liver oil and halibut-liver oil are very rich in vitamin A. It is absent in vegetable fats and oil examples are linseed oil, groundnut oil, olive oil. Margarine is made from these oils and vitamin $\mathrm{A}$ is added during the manufacture. It is stored in the liver.

Two vitamin A molecules joined together with the elimination of the $\mathrm{OH}$ groups give a carotene. Carotenes are found in green vegetables and carrots. They are converted to vitamin $\mathrm{A}$ in the body.

Vitamin A is essential for the regeneration of visual purple in the eye, which is bleached by bright light. A failure or delay in dark adaptation (night blindness) is one of the earliest signs of vitamin Adeficiency ${ }^{2}$.

Vitamin A aldehyde (retinaldehyde), a derivative of vitamin A combines with the protein opsin and forms visual purple (rhodopsin). Light splits this molecule into vitamin A aldehyde and opsin ${ }^{1}$.

Vitamin Aaldehyde + opsin $=$ Visual purple RHODOPSIN (Protein)

Seventy to ninety percent of vitamin A from the diet is absorbed in the intestine. The efficiency of absorption for vitamin A continues to be high as intake continues to increase ${ }^{3}$.

B- carotene is an orange pigment found in carrots and other plant tissues. It has the biologic potency of vitamin A. The B- carotene is oxidatively cleaved by the intestinal mucosa into two retinal molecules, each of which is then reduced to all trans-retinol ${ }^{4}$. Free retinol is absorbed into the intestinal mucosa where it is esterified with a fatty acid such as palmitate and then transported in the lymph to the liver. Absorption of vitamin A is very rapid, with maximum absorption occurring two to six hours after digestion ${ }^{5}$. In average doses, peak concentrations are reached in 4hours ${ }^{3}$. Most ingested retinol is stored in the liver. Retinol storage has a half-life of 50-100 days ${ }^{6}$.

Vitamin A deficiency is the most prevalent nutritional disorder in the world. It is rampant in south East Asia, parts of China and Africa, and many other third world countries? ${ }^{7}$. The well established consequences of vitamin A deficiency are xerophthalmia, keratomalacia, corneal scarring and blindness, impaired maintenance of special epithelia with squamous metaplasia of transitional epithelium and columnar mucus- secreting surface and impaired immune responses with increased mortality from infection. Possible consequences of vitamin A deficiency are impaired reproduction, impaired skeletal growth and increased predisposition to cancer of the skin, lungs and other 
sites $^{7}$.

If blinking is prevented for a prolonged period of time, the tear film breaks-up, with the formation of dry spots. Tear film break-up time (TBUT) is defined as the interval between a complete blink and the first randomly distributed dry spots. TBUT is used as an index to measure abnormal tear formation. It is usually low in abnormal or pathological situations. With normal subjects, the majority of break up times fell in the 15 to 34 seconds range. A break up time of less than 10 seconds is usually considered a negative factor in patients' selection in contact lens wear.

Patients with break-up time of less than 10 seconds have been found to have abnormally low or nonexistent goblet cell populations even though they have adequate aqueous tear ${ }^{8}$. The most obvious cause of a deficient goblet cell population is vitamin A deficiency.

\section{MATERIALS AND METHOD}

The study was centered in Owerri Urban in Imo State, Nigeria. All the subjects used were resident in the urban areas of Owerri, capital of Imo State.

A total 100 subjects who are students of Imo State University, comprising 50 males and 50 females between the ages of 18 and 30years of age made up the study population. The age bracket above was chosen because it represents the young adults of Imo State University upon which this study was based.

Data collection involved the measurement of the TBUT of the subjects before and after the administration of vitamin A. The TBUT of the subjects were measured in seconds.

The following materials and instruments were used in the collection of data: fluorescein strip, slit lamp biomicroscope, ophthalmoscope, stop watch, vitamin A tablets $(50,000$ international units per tablet), pen torch, normal saline, cotton wool.

A brief history was taken on subjects to ensure that they were in good health. Then the slit lamp biomicroscope was used to carry out an external examination on the subjects. This was a precautionary measure to ensure that there were no pathologies present in the subjects' anterior segment of the eyes. The presence of any pathology could interfere with the results obtained. The ophthalmoscope was also used to examine the fundus and the interior of the eyes to rule out any pathology of the posterior segment.

The TBUT was then measured and recoded before the commencement of the oral intake of the vitamin A tablets. The vitamin A tablet was then administered on a regimen of one tablet per day for seven consecutive days. This is the normal dosage for administration of vitamin A tablets. The TBUT was then measured on the $20^{\text {th }}$ day. This is because of the fact that vitamin A is readily absorbed within 4-6 hours after consumption and has a half-life of 50-100days ${ }^{3}$ and for this period, will continue to be transported to the target tissues. Thus in 20 days, the vitamin A has reached the tissues of the eye and had caused the desired effect. The measurements recorded after 20 days of vitamin A administration was compared with the TBUT before the vitamin A administration in order to determine if the intake of vitamin A had a pronounced effect on the stability of the pre-corneal film.

The subject was asked to sit down and relax on a chair with his/ her face up. The tip of the fluorescein strip was gently inserted into the inferior fornix. The subject was asked to close his/her eyes for about 15 seconds after which the tear film had been stained completely by the fluorescein.

The subject facing towards the slit lamp biomicroscope was asked to blink several times and stop. The subject was cautioned not to blink again while the tear film was examined with a broad beam and a cobalt blue filter. A black sport or line indicated the formation of a dry area. The TBUT is the time interval between the last blink and the formation of the first black sport or line. This was measured with a stop watch. The TBUT was then recoded in seconds. The normal saline was used to rinse the eyes and dried with the cotton wool.

Data obtained was analyzed using the Spearman rank- order correlation coefficient to determine the strength of association between the TBUT values before and after vitamin A administrations. Bar chart, pie chart, tables and figures were used to present results obtained for the analysis of data.

\section{RESULTS}

The tear break-up time was measured on 100 subjects; 50 males and 50 females, all within the 
ages of 18 and 30 . The measurements were carried out before the administration of vitamin A and 20 days after a 7-day administration of vitamin A.

\section{DISCUSSION}

A general view of all the subjects, both males and females together showed that before the administration of vitamin A, the range of TBUT values were 13-28 seconds. The pie chart in fig. 2 showed that $35 \%$ of the subjects had a TBUT value within the 16-18seconds group while $31 \%$ had a TBUT value in the 19-21 seconds group. Thus, majority of the TBUT values then fell within 16-21 seconds. After the administration of vitamin A, the range became 16-31 seconds. Majority of the TBUT values then fell within 19-24 seconds with $32 \%$ in $19-21$ seconds group and $29 \%$ in $22-24$ seconds group. The mean TBUT also increased to 21.79 seconds indicating an increase in 2.67 seconds.

The difference in TBUT before and after the administration of vitamin A for the males, females and combination of both is observed that the TBUT difference rages from $0-+6$ seconds. The difference in the mean TBUT for the males and females is insignificant. A combination of both males and females showed that majority of the subjects had a TBUT difference of +2 seconds (26\%) and +3 seconds $(25 \%)$.

Upon measurement of the correlation between the two observations using the Spearman rankorder, the critical value of 'rho' (at N-100, 0.05 Level of significance) was found to be lower (0.236) than the calculated value of 'rho' (0.9952). Therefore there is a significant difference in TBUT before and after vitamin A administration. From the results of this study, an increased intake of vitamin A increased the TBUT, which resulted to an increase in the tear film stability.

This conclusion is in conformity with that reached by $\mathrm{Patel}^{8}$, who found that vitamins and trace element supplements had a remarkable enhancing effect on the stability of the pre-corneal tear film. Also Garrett ${ }^{9}$ found an improvement in dry eye symptoms with the administration of multivitamins and topical vitamin A on presbyopic soft contact lens wearers. Results obtained from this study showed that the increased intake of vitamin A led to a significant increase in TBUT values; thus improving the stability of the precorneal tear film.

TABLE 1: FREQUENCY OF GROUPED TBUT VALUES IN BOTH MALES AND FEMALES BEFORE VITAMIN A ADMINISTRATION

\begin{tabular}{|c|c|c|}
\hline $\begin{array}{l}\text { TBUT } \\
\text { (seconds) }\end{array}$ & $\begin{array}{l}\text { Absolute } \\
\text { frequency }\end{array}$ & $\begin{array}{l}\text { Percentage } \\
\text { frequency }(\%)\end{array}$ \\
\hline $13 \ddot{i} 15$ & 13 & 13 \\
\hline $16 \ddot{i} 18$ & 35 & 35 \\
\hline $19 \ddot{i} 21$ & 31 & 31 \\
\hline $22 \ddot{i} 24$ & 14 & 14 \\
\hline 25 ï 27 & 6 & 6 \\
\hline $28 \ddot{i} 30$ & 1 & 1 \\
\hline
\end{tabular}

TABLE 2: FREQUENCY OF GROUPED TBUT VALUES IN BOTH MALES AND FEMALES AFTER VITAMIN A ADMINISTRATION

\begin{tabular}{|c|c|c|}
\hline $\begin{array}{l}\text { TBUT } \\
\text { (Seconds }\end{array}$ & $\begin{array}{l}\text { Absolute } \\
\text { Frequency }\end{array}$ & $\begin{array}{l}\text { Percentage } \\
\text { Frequency }\end{array}$ \\
\hline $16 \ddot{i} 18$ & 20 & 20 \\
\hline 19 ï 21 & 32 & 32 \\
\hline 22 ï 24 & 29 & 29 \\
\hline 25 ï 27 & 12 & 12 \\
\hline 28 ï 30 & 6 & 6 \\
\hline 31 ï 33 & 1 & 1 \\
\hline
\end{tabular}




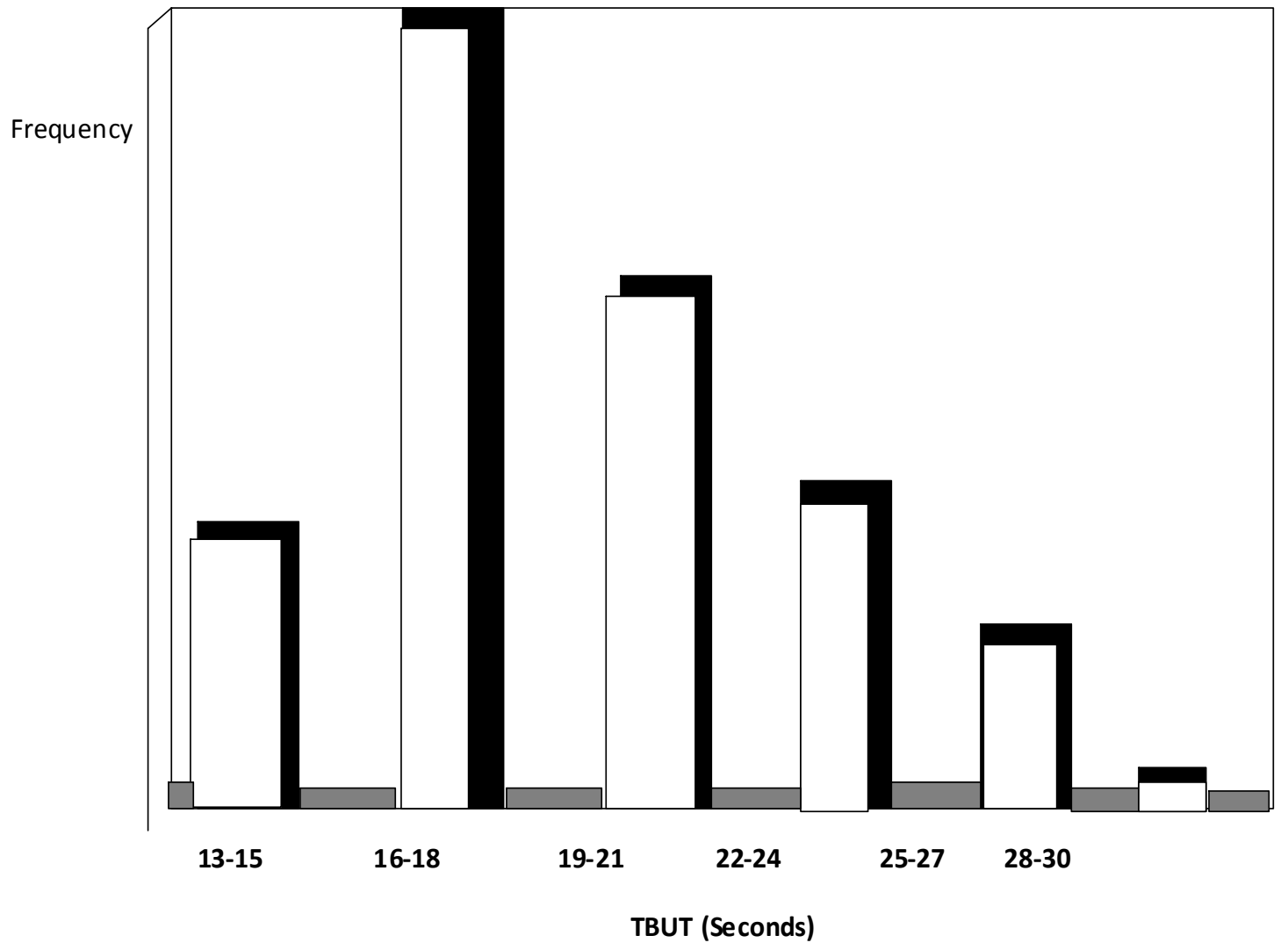

FIG. 1: GROUPED TBUT VALUES IN BOTH MALES AND FEMALES AFTER VITAMIN A ADMINISTRATION

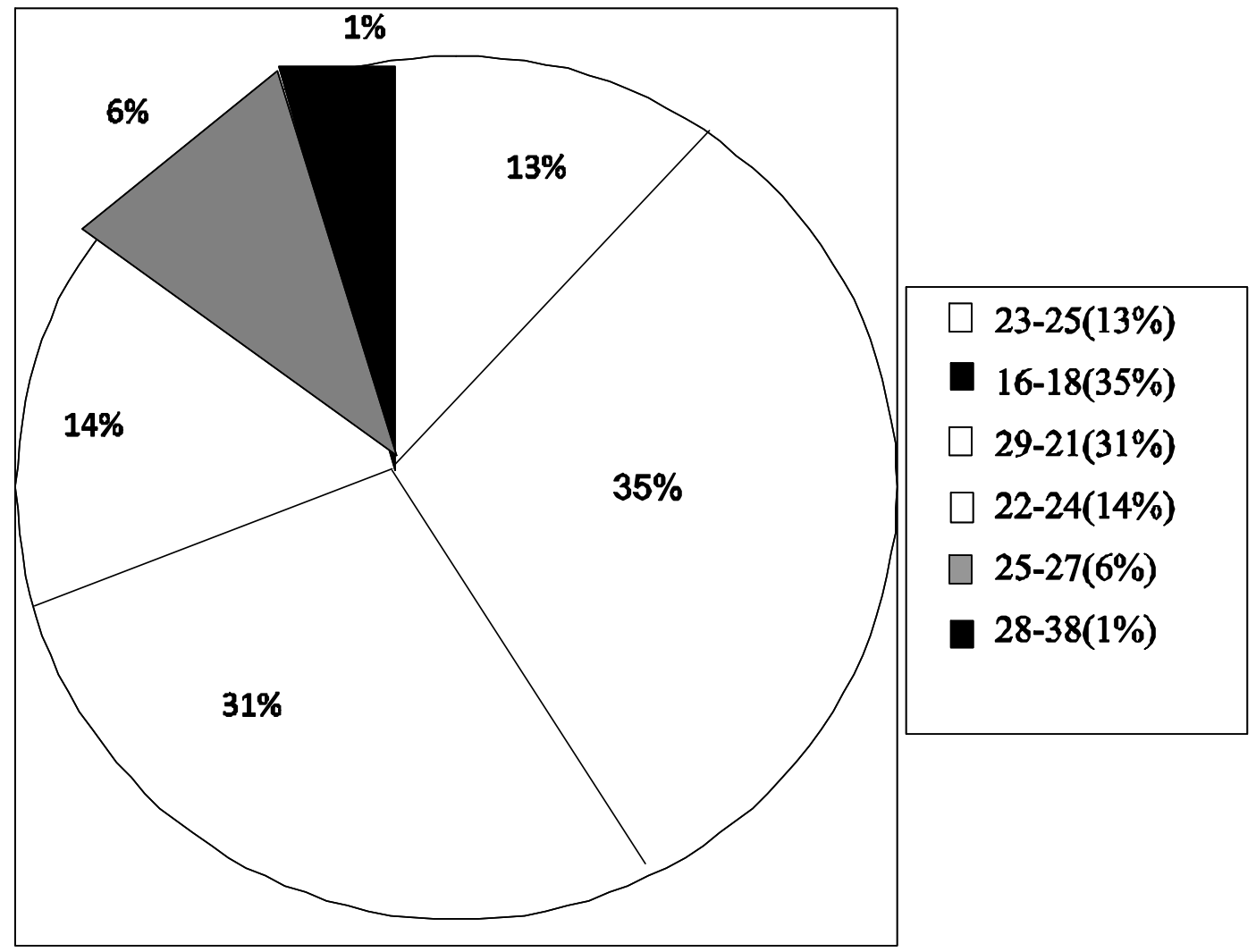

FIG. 2: PERCENTAGE FREQUENCY OF GROUPED TBUT VALUES IN MALES AND FEMALES BEFORE VITAMIN A ADMINISTRATION 


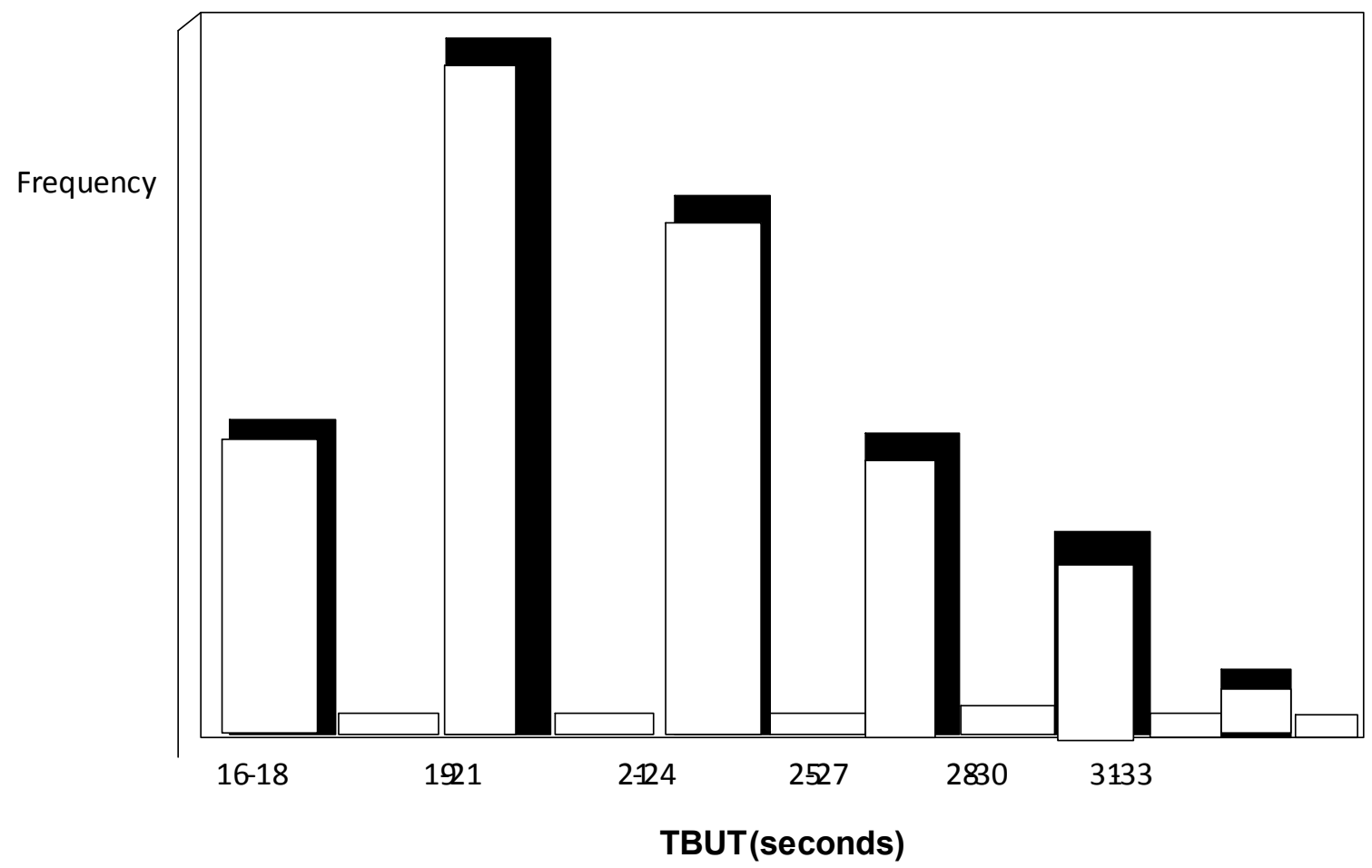

FIG. 3: GROUPED TBUT VALUES IN BOTH MALES AND FEMALES AFTER VITAMIN A ADMINISTRATION

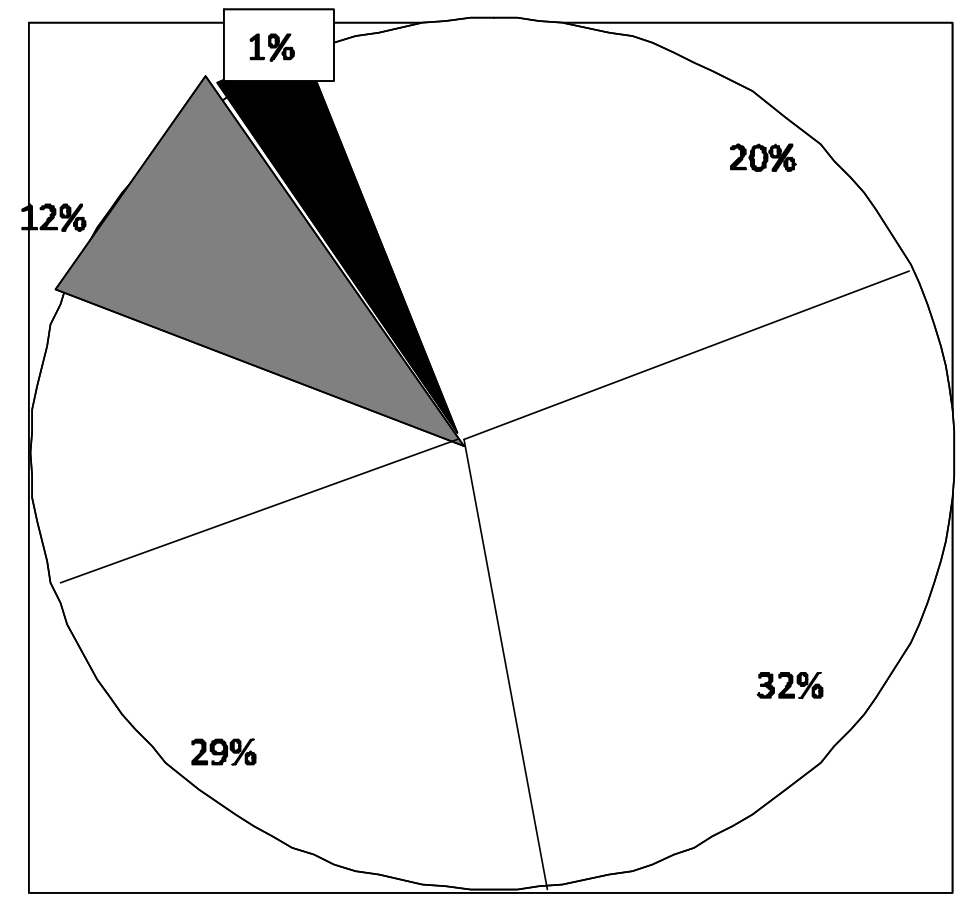

$\square 16-18$ (20\%)

$\square 19-21(32 \%)$

$\square 22-24(29 \%)$

$\square$ 25-27 (12\%)

$\square 28-30$ (6\%)

- 31-33(1\%)

FIG. 4: PERCENTAGE FREQUENCY OF GROUPED TBUT VALUES IN BOTH MALES AND FEMALES AFTER VITAMIN A ADMINISTRATION 
1) Green, J. (1981): An introduction to Human physiology. $4^{\text {th }}$ Edn. Oxford University Press, pp211-20.

2) Macleod, J. Edwards, C., and Bouchier, I. (1990): Principles and Practice of Medicine. $5^{\text {th }}$ Edn. Education Low-Priced Books Scheme, pp 38-50.

3) Shekelle, R. B. (1981): Dietary Supplements as Ergogeric Aids. Lancet, 326-31.

4) Montgomery, W., Conway, J., and Spector, V. (1990): Biochemistry: Case oriented approach. $5^{\text {th }}$ Edn. The C. V. Mosby Company
5) RBP, USAID Health Technical Program, 1998.

6) Ross, A. C. (1999): Vitamin A: Modern Nutrition in Health and Disease. Baltimore, Williams and Wilkns, 305-13.

7) Hennekens, C. H. (1996): Vitamin A; Nutrition vitamins and trace minerals. New Eng. J. Med, 334: 145-9.

8) Robbins, S. L. and Cotran, R. S. (1995): Pathologic Basis of Diseases. $7^{\text {th }}$ Edn. Saunders Company

9) Patel, K.: The influence of vitamins an 